\title{
道路桥梁施工技术与管理研究
}

\author{
常乃坤 \\ 安徽省路桥工程集团有限责任公司，安徽 合肥 230031
}

[摘要]近年来, 在多方面利好因素的带动下，使得我国社会经济整体水平得到了显著的提升，从而为我国道路桥梁工程行业 的发展壮大带来了良好的机遇。但是就当下我国道路桥梁工程施工工作实际情况来看, 与其他发达国家的整体水平还存在一 定的差距, 并且施工技术方面还存在诸多弊端, 还需要我们进一步的进行深入的研究分析。道路桥梁工程是城市之间连接的 纽带, 并且在推动社会经济稳步发展方面具有非常重要的影响作用。社会的飞速发展, 从而推动了我国道路桥梁工程的稳步 发展, 但是因为道路桥梁工程工程施工周期较长, 覆盖范围较为广泛, 所以往往会受到诸多外界因素的影响, 无法从根本上 对工程施工质量和效率加以保证。要想有效的解决上述问题, 最为重要的就是需要利用有效的方式方法来提升道路桥梁工程 施工技术水平，并全面的落实道路桥梁工程施工管理工作。

[关键词]道路桥梁工程; 施工技术; 工程管理；工程质量

DOI：10.33142/ec.v3i5.1908 中图分类号：U445.1 文献标识码：A

\section{Research on Construction Technology and Management of Road and Bridge}

\author{
CHANG Naikun
}

Anhui Road and Bridge Engineering Group Co., Ltd., Hefei, Anhui, 230031, China

\begin{abstract}
In recent years, driven by many favorable factors, the overall level of social economy in China has been significantly improved, which brings good opportunities for the development and expansion of Chinese road and bridge engineering industry. However, according to the actual situation of road and bridge engineering construction in our country, there is still a certain gap with the overall level of other developed countries and there are many disadvantages in construction technology, which need further research and analysis. Road and bridge engineering is the link between cities and plays a very important role in promoting steady development of social economy. The rapid development of society has promoted the steady development of road and bridge engineering in China. However, due to long construction period and wide coverage of road and bridge engineering, it is often affected by many external factors, which can not guarantee construction quality and efficiency fundamentally. In order to solve the above problems effectively, the most important is to use effective methods to improve the level of road and bridge engineering construction technology and implement the road and bridge engineering construction management comprehensively.
\end{abstract}

Keywords: road and bridge engineering; construction technology; engineering management; engineering quality

引言

随着社会经济的发展, 道路桥梁工程建设也变得越来越复杂, 对其提出的要求也越来越高, 这就使得道路工程施工 技术及管理工作达到更高的要求。本文将分析道路桥梁工程施工中出现的技术以及管理上的问题并提出相关解决措施。

\section{1 道路桥梁施工技术管理}

道路桥梁工程施工技术与管理工作其实质就是在组织开展道路桥梁工程施工工作的时候, 工程施工单位严格遵照 相关行政机构制定的规范标准, 针对工程施工过程中的各项工序以及施工技术进行统一安排和管控, 从而在确保道路 桥梁工程施工质量和施工效率的基础上, 促进工程施工技术水平的不断提升, 为我国道路桥梁工程行业的稳步发展创 造良好的基础。在组织开展道路桥梁工程施工工作的时候, 因为对工程施工质量的要求较高, 所以在选择施工技术方 面务必要综合各方面情况加以判断。道路桥梁工程各项施工技术之间存在明显的差异, 从而造成了施工质量与施工方 案也是不尽相同的 ${ }^{[1]}$ 。所以在开展工程施工工作的过程中, 务必要从各个环节入手来对道路桥梁施工技术进行全面的管 控, 确保各个工序的质量能够达到规定的要求, 并且还需要切实的落实施工监管工作, 避免违规情况的发生。

\section{2 道路和桥梁施工技术现状}

\section{1 缺乏施工管理技术}

就当下道路桥梁工程施工管理工作的实际情况来看, 整体水平并没有达到完善的状态, 其中还存在诸多的问题需 
要我们进一步的加以解决。在针对桥梁工程施工工作进行管理的时候, 需要对各项管理工作的落实进行详细的记录。 其次, 管理工作人员综合素质水平存在高低不一致的情况, 很多管理工作人员资质较差, 所以无法严格的遵照规范标 准来开展工程施工管理工作, 从而会对各项信息数据的完整性造成一定的损害。施工材料的质量与工程施工效果和质 量密切相关, 如果施工材料的质量不能达到规定的标准, 那么必然会对工程施工质量造成严重的损害。但是在道路桥 梁工程施工中, 部分工程施工单位为了一己私利, 往往会为了缩减工程成本而选择成本较少但是质量低劣的施工材料, 这样对于保证工程施工质量来说是非常不利的。道路桥梁工程施工工作使用最为频繁的就是混凝土物料, 但是混凝土 材料的质量因为与外界各种因素存在密切的关联, 所以如果不能加以切实的管控极易发生结构裂缝的情况 ${ }^{[2]}$ 。

\section{2 钢筋易腐蚀}

就道路桥梁工程结构实际情况来看, 钢筋物料可以说是其中最为关键的一种支撑材料, 如果不能对钢筋材料的质 量加以保护, 而导致钢筋出现腐蚀的情况, 那么不但会损害到道路桥梁工程整体施工质量, 并还会对民众的人身安全 产生一定的威胁。经过事件调查我们发现, 诱发道路桥梁钢筋结构发生腐蚀的情况的因素有很多, 诸如: 工程施工材 料质量不达标, 施工工序中存在诸多失误的情况等等, 所以要想避免钢筋发生腐蚀的情况, 就需要工程施工管理工作 人员严格遵照规范标准对各项工作进行切实的管控 ${ }^{[3]}$ 。

\section{3 道路桥梁施工管理能力不足}

在实际组织开展施工工作的过程中, 因为我国道路桥梁工程大都是由某个施工单位进行承建的, 所以施工管理工 作也是统一由承建单位担负, 如果施工管理工作效果较差, 那么就无法从根本上对此工程的施工质量加以保证。或者 是承建单位施工管理工作人员专业能力较差, 那么也会对施工管理工作的开展造成诸多的限制。因为施工管理工作人 员大都专业水平较差, 并且很多施工管理工作人员身兼数职, 所以无法保证管理工作的效率和质量。

\section{3 道路桥梁工程中应用到的施工技术}

\section{1 真空压浆技术}

根据传统压浆工艺改造基础得出真空压浆技术, 属于真空技术与压浆技术的有效融合。是可以解决压力不足的问 题以及减少施工时间的优秀技术。在道路桥梁工程施工中运用真空压浆技术对道路桥梁的质量大有裨益 ${ }^{[4]}$ 。

\section{2 体外索加固法}

体外索加固法可以帮助施工人员对道路桥梁结构的受力情况进行调整, 以保障道路桥梁工程的承载力和抗裂程度。 易于操作也是体外索加固法的一大优点, 对车辆出行造不成影响也是优点之一。

\section{3 大跨径连续桥梁施工技术}

大跨径连续桥梁施工技术主要应用于趋向大跨度方向发展的道路桥梁建设工程上, 而悬臂法就是这其中的主要代 表方法。这也是能够满足经济与技术发展前提下的对道路桥梁施工技术提出的更高的要求的需要。

\section{4 道路桥梁工程的施工的技术要求}

\section{1 路面的稳定}

作为道路桥梁施工的质量的影响因素之一的路面, 其强度需要得到保障。路面具有一定的强度才可以抵抗外力的 作用, 此外还需保证路面的耐高温性、抗裂性和大气稳定性等, 这样道路结构才不会受到一些天气的影响。路面的稳 定也可在一定程度上保证道路桥梁的稳定性 ${ }^{[5]}$ 。

\section{2 对路面进行防护}

由于环境对于道路桥梁施工质量的影响, 施工人员还必须做好路面防护工作, 以避免由于环境对路面的影响而导 致对道路桥梁施工质量造成影响。做好路面防护工作需要加强路面结构防护。

\section{3 增加路面耐久度}

路面耐久度在一定程度上会影响路面的结构是否变形, 也会导致路面受到破坏, 甚而可能会出现路面结构材料老 化的现象, 因而需要增强路面的耐久度。

\section{4 做好路面排水处理}

路面排水系统在排水方面做得是否到位在一定程度上影响了交通出行的安全性。由于排水系统主要用于排除地下 水以及地表水, 因而在排水不及时的情况下会严重影响路况, 会出现道路危险以及影响路面质量的情况, 严重者可能 导致路面的结构发生变化, 因而一定要做好路面排水处理工作 ${ }^{[6]}$ 。 


\section{5 合理运用软土路基处理技术}

软土地基是道路桥梁施工过程中常常遇到的情况, 因而要选择合适的方法对其进行处理。一般要根据实际施工情 况进行方式的选用, 切不可盲从经验而胡乱选用方法, 以免经验主义导致大的问题的出现。

\section{5 加强道路和桥梁施工技术管理的有效措施}

\section{1 不断完善道路和桥梁施工技术的管理体系}

在针对道路桥梁工程施工技术质量加以管控的时候, 施工单位不但要对项目工程经济效益加以重视, 并且还应当 创设完善的道路桥梁工程施工技术质量管理机制, 从而保证施工质量能够达到既定的标准水平。在综合各方面因素来 创建道路桥梁工程施工技术质量管理机制的过程中, 务必要对三检制度加以落实。三检制度其实质就是：自检、互检、 专项检查。其次, 需要将工作人员划分为几个小组, 以小组未核心来设计质量检验自检制度, 这样才能保证自检工作 的效果。

\section{2 对桥梁施工技术进行全方位的管理}

桥梁工程施工工作涉及到的层面较多, 所以具有非常明显的复杂性, 要想切实的保证桥梁工程施工技术的效果以 及工程整体施工质量, 那么就需要从施工材料、机械设备、工程施工工序等多个方面来全面落实管理工作。首先, 需 要加大力度来针对桥梁工程原材料进行全面的管控。桥梁工程施工过程中需要使用到大量的不同类型的施工材料, 并 且施工材料的质量往往都与工程施工质量密切相关, 所以需要加强施工原材料的管理力度, 避免质量低劣的施工材料 运用到施工工序之中 ${ }^{[7]}$ 。其次, 加强对桥梁施工设备管理机械设备是铁路桥梁施工技术应用的基础和前提，并在一定 程度上影响了施工的进度和质量。因此, 必须要加强对设备的管理, 做到定期检查、做好使用管理记录、制定保养和 维修计划等。另外, 还要定期引进、更换新的机械设备, 保证施工安全。最后, 加强对桥梁施工现场的管理在桥梁施 工过程中, 施工现场的管理, 是整个管理的核心。在具体的桥梁施工过程中, 特别是跨铁路桥梁施工中, 在有限的施 工时间内, 必须要加强对施工现场的管理, 加强人员的监控和协调, 确保现场各个结构施工质量达到设计要求, 保证 桥梁工程的质量。

\section{3 提高工作人员的素质、安全质量意识}

加强道路桥梁工程施工技术质量管理体系建设, 还必须要采取一定的手段, 不断提高相关工作人员的质量意识和 综合素质。首先, 对专业人员进行培训和考核, 必要时可进行人员资格、技术水平认证, 对所有参与跨铁路施工的人 员, 必须组织进行铁路施工安全技术培训, 所有参与施工人员必须考试合格; 其次, 还要组织相关工作人员进行观摩 学习, 不但要提高相关工作人员的专业知识水平, 还要不断提升其职业道德素质。

\section{结语}

综合以上阐述我们总结出, 要想推动道路桥梁工程行业的稳步发展, 最为重要的就是要综合各方面实际情况来推 进桥梁工程施工技术的不断完善和优化。现如今, 在社会快速发展的过程中, 人们的思想意识出现了明显的变化, 对 于公路桥梁工程施工质量和安全提出了更高的要求。总之, 施工方法能够保护道路和桥梁的质量, 是我国交通运输中 不可或缺的一部分，因此，提高施工技术水平，以促进改善道路和桥梁。

\section{[参考文献]}

[1]夏晓磊.道路桥梁施工技术与管理分析 [J].建材与装饰, 2020(08): 251-252.

[2]李旭芝.城市道路桥梁施工技术与管理 [J].智能城市, 2020,6 (05) : 169-170.

[3] 任宗祥. 道路桥梁施工技术管理 [J]. 工程技术研究, 2020, 5 (04) : 182-183.

[4]陈大峰.道路桥梁施工技术与管理 [J].河南科技, 2020(05): 99-101.

[5]李建文. 道路桥梁施工技术与管理 [J]. 河南建材, 2020(01): 67.

[6]冯义. 道路桥梁工程施工技术管理问题思考 [J]. 门窗,2019(23) : 100.

[7]王雪柏. 道路桥梁施工技术与管理 [J]. 门窗, 2019 (23) : 125.

作者简介: 常乃坤 $\left(1978^{-}\right)$, 男, 安徽省合肥市, 汉族, 本科学历, 工作方向为路桥施工。 